\title{
Efficacy of nitric oxide, with or without continuing antihypertensive treatment, for management of high blood pressure in acute stroke (ENOS): a partial-factorial randomised controlled trial
}

The ENOS Trial Investigators*

\section{Summary}

Background High blood pressure is associated with poor outcome after stroke. Whether blood pressure should be lowered early after stroke, and whether to continue or temporarily withdraw existing antihypertensive drugs, is not known. We assessed outcomes after stroke in patients given drugs to lower their blood pressure.

Methods In our multicentre, partial-factorial trial, we randomly assigned patients admitted to hospital with an acute ischaemic or haemorrhagic stroke and raised systolic blood pressure (systolic 140-220 mm $\mathrm{Hg}$ ) to 7 days of transdermal glyceryl trinitrate $(5 \mathrm{mg}$ per day), started within $48 \mathrm{~h}$ of stroke onset, or to no glyceryl trinitrate (control group). A subset of patients who were taking antihypertensive drugs before their stroke were also randomly assigned to continue or stop taking these drugs. The primary outcome was function, assessed with the modified Rankin Scale at 90 days by observers masked to treatment assignment. This study is registered, number ISRCTN99414122.

Findings Between July 20, 2001, and Oct 14, 2013, we enrolled 4011 patients. Mean blood pressure was 167 (SD 19) $\mathrm{mm} \mathrm{Hg} / 90$ (13) $\mathrm{mm} \mathrm{Hg}$ at baseline (median $26 \mathrm{~h} \mathrm{[16-37]} \mathrm{after} \mathrm{stroke} \mathrm{onset),} \mathrm{and} \mathrm{was} \mathrm{significantly}$ reduced on day 1 in 2000 patients allocated to glyceryl trinitrate compared with 2011 controls (difference $-7 \cdot 0$ [95\% CI $-8 \cdot 5$ to -5.6$] \mathrm{mm} \mathrm{Hg} /-3 \cdot 5[-4 \cdot 4$ to $-2 \cdot 6] \mathrm{mm} \mathrm{Hg}$; both $\mathrm{p}<0.0001)$, and on day 7 in 1053 patients allocated to continue antihypertensive drugs compared with 1044 patients randomised to stop them (difference $\mathbf{- 9} .5$ [95\% CI $-11 \cdot 8$ to $-7 \cdot 2] \mathrm{mm} \mathrm{Hg} /-5 \cdot 0$ [-6.4 to -3.7] $\mathrm{mm} \mathrm{Hg}$; both p<0 0001). Functional outcome at day 90 did not differ in either treatment comparison-the adjusted common odds ratio (OR) for worse outcome with glyceryl trinitrate versus no glyceryl trinitrate was 1.01 (95\% CI $0.91-1 \cdot 13 ; \mathrm{p}=0.83)$, and with continue versus stop antihypertensive drugs OR was $1.05(0 \cdot 90-1 \cdot 22 ; \mathrm{p}=0 \cdot 55)$.

Interpretation In patients with acute stroke and high blood pressure, transdermal glyceryl trinitrate lowered blood pressure and had acceptable safety but did not improve functional outcome. We show no evidence to support continuing prestroke antihypertensive drugs in patients in the first few days after acute stroke.

Funding UK Medical Research Council.

Copyright (C) Bath et al. Open Access article distributed under the terms of CC BY.

\section{Introduction}

High blood pressure is present in $70 \%$ or more of patients with acute ischaemic stroke ${ }^{1}$ or haemorrhagic stroke. Affected patients have a worse outcome, whether judged as early recurrence, death within a few weeks, or combined death and dependency after several months. ${ }^{1-4}$ Lowering of blood pressure acutely after stroke might therefore reduce these events and improve functional outcome, providing that cerebral perfusion is not reduced in the presence of dysfunctional cerebral autoregulation. Several large trials have tested the safety and efficacy of individual drugs or management strategies that lower blood pressure, with investigators reporting results for functional outcomes ranging from near-negative (SCAST) ${ }^{5}$ to neutral (IMAGES, ${ }^{6}$ CATIS), ${ }^{7}$ to near-positive (INTERACT-2). ${ }^{8}$ With use of meta-regression, a U-shaped relation was shown between outcome and difference in blood pressure between treatment groups in previous trials, with both large reductions or any increase in blood pressure associated with a worse functional outcome. ${ }^{9}$

Nitric oxide donors are candidate treatments for acute stroke because of several effects-nitric oxide is a cerebral and systemic vasodilator that lowers blood pressure, modulates vascular and neuronal function, is neuroprotective, and inhibits apoptosis. ${ }^{10}$ In preclinical studies of cerebral ischaemia, nitric oxide donors reduced infarct lesion size and improved regional cerebral blood flow and functional outcome. ${ }^{11}$ Five small clinical studies of nitric oxide donors have been done: ${ }^{12-16}$ intravenous sodium nitroprusside reduced blood pressure without changing cerebral blood flow and had antiplatelet effects, ${ }^{12}$ thereby precluding its use in haemorrhagic stroke. In four pilot trials, ${ }^{13-16}$ transdermal glyceryl
Lancet 2015; 385: 617-28 Published Online October 22, 2014 http://dx.doi.org/10.1016/ S0140-6736(14)61121-1

This online publication has been corrected. The corrected version first appeared at thelancet.com on February 13, 2015 See Comment page 582 *Members listed in appendix Correspondence to: Prof Philip M W Bath, Stroke Trials Unit, Stroke, Division of Clinical Neuroscience, University of Nottingham, Nottingham NG5 1PB, UK

philip.bath@nottingham.ac.uk See Online for appendix 
For the full ENOS protocol see http://www.nottingham.ac. uk/ nszwww/enos/ enosprotocolv15.pdf trinitrate lowered blood pressure, had no negative effects on platelet function, did not change middle cerebral artery blood flow velocity or regional cerebral blood flow, improved aortic compliance, and could be given to patients with dysphagia. No safety concerns were present in these studies, and in one small single-centre trial, functional outcome was improved with glyceryl trinitrate when given within $4 \mathrm{~h}$ of stroke onset. ${ }^{16}$

Treatment of hypertension effectively prevents first and recurrent stroke. ${ }^{17,18}$ As a result, many patients are taking blood pressure-lowering drugs at the time of any subsequent stroke. A common clinical problem is whether these drugs should be continued or stopped temporarily during the acute phase after stroke; the answer remains unclear, ${ }^{19}$ guidelines mostly ignore the question, and clinical practice varies. ${ }^{20}$ The multicentre Continue or Stop Post-Stroke Antihypertensives Collaborative Study $(\mathrm{COSSACS})^{21}$ examined this question and reported, in 763 patients, that continuing antihypertensive drugs, as compared with stopping them, did not change death or dependency at either 2 weeks or 6 months.

Continuing antihypertensive drugs might help to reduce early recurrence and haematoma expansion, and improve functional outcome after stroke, much as long-term blood pressure reduction reduces recurrence; ${ }^{18}$ by preventing rebound increases in blood pressure and heart rate (when $\beta$ blockers are stopped), which might induce stroke recurrence and myocardial infarction, respectively; and by ensuring that antihypertensive drugs are continued beyond hospital discharge. Alternatively, stopping treatment temporarily might be advantageous for several reasons. First, some antihypertensive drugs might be hazardous when started in acute stroke, as reported in trials of angiotensin-receptor antagonists, $\beta$ blockers, and calcium-channel blockers. ${ }^{22-24}$ Second, many patients do not take their blood pressure drugs regularly, and so correct administration of these drugs in hospital can lead to large and potentially harmful falls in blood pressure. ${ }^{25}$ Third, antihypertensive drugs can cause substantial hypotension in the presence of hypovolaemia and dehydration, which are commonly present in patients with acute stroke who might not be taking fluids appropriately. Fourth, stopping of treatment might increase perfusion through collateral vessels and optimise salvage of penumbral tissue. Fifth, blood pressure-lowering drugs might worsen cerebral perfusion in the presence of severe ipsilateral carotid artery stenosis. Sixth, drugs taken orally could lead to aspiration and pneumonia in the presence of dysphagia. Finally, oral administration of drugs might not be possible if the patient has dysphagia and enteral access has not yet been done; furthermore, those antihypertensive drugs that are embedded in a slow-release or modified-release mechanism are not suitable to be taken via nasogastric tubes. As a result, continuation of treatment immediately after admission might not be possible in many patients after stroke.
We report the findings of the Efficacy of Nitric Oxide in Stroke (ENOS) partial-factorial randomised controlled trial. We aimed to assess the safety and efficacy of glyceryl trinitrate given within $48 \mathrm{~h}$ to patients with acute ischaemic or haemorrhagic stroke and high blood pressure. We also aimed to assess outcomes for a subset of patients who continued or stopped taking antihypertensive drugs for 1 week after their stroke.

\section{Methods}

\section{Participants}

Between July 20, 2001, and Oct 14, 2013, we did an international multicentre randomised, placebo-controlled patient-masked, outcome-assessor-masked, parallel-group trial. The full ENOS protocol is available online. Details of the design and statistical analysis plan have been published ${ }^{26,27}$ and are summarised in the appendix. In brief, patients were randomly assigned to 7 days of treatment with transdermal glyceryl trinitrate (also known as nitroglycerin, nitroglycerine, or trinitroglycerin) or no glyceryl trinitrate. In addition, a subset of patients who were taking blood pressure-lowering drugs immediately before their stroke were randomly assigned to continue or stop these drugs temporarily in a partial-factorial design. ${ }^{26}$

Patients were eligible for the trial if they were admitted to hospital with a clinical stroke syndrome due to ischaemic or haemorrhagic stroke, were aged 18 years or older, had a motor deficit in their arm or leg or both, had a systolic blood pressure of $140-220 \mathrm{~mm} \mathrm{Hg}$, and could be treated within $48 \mathrm{~h}$ of onset. ${ }^{26}$ The diagnosis of ischaemic or haemorrhagic stroke was confirmed with CT or MRI done before or by 7 days after enrolment with standard imaging techniques. Key exclusion criteria included a definite need to start (eg, for thrombolysis), continue, or stop blood pressure-lowering drugs; need for, or contraindication to, glyceryl trinitrate; coma (Glasgow coma scale score <8); pure sensory stroke; isolated dysphasia; preceding moderate or severe dependency (modified Rankin scale [mRS] score 3-5); confounding neurological or psychiatric disease; a disorder mimicking stroke (eg, hypoglycaemia, Todd's paresis); liver dysfunction (international normalised ratio $>1 \cdot 5$, aminotransferase more than three-times normal concentrations) or renal dysfunction (creatinine more than three-times normal concentrations); severe concomitant medical disorder; pregnancy or breastfeeding; previous participation in ENOS; planned surgical intervention; or participation in another trial within 2 weeks.

The study was approved by national and local ethics committees and competent authorities in each participating country and site, and was adopted by the Australian, Canadian, and UK National Institute for Health Research Stroke Research Networks. The trial was overseen by a trial steering committee (which included three independent members) and an international advisory committee (which comprised each national 
coordinator). The day-to-day conduct of the trial was run by a trial management committee that was based at the coordinating centre in Nottingham, UK. An independent data monitoring committee reviewed unmasked data every 6 months. We obtained written informed consent from each patient, or from a relative or independent physician when the patient did not have capacity, before enrolment and in accordance with national regulations.

\section{Randomisation}

Investigators entered baseline and follow-up data into a database via a secure web-based randomisation system. The data were checked to confirm the patient's eligibility in real time, and the computer system assigned participants, with one to one allocation, to glyceryl trinitrate or no glyceryl trinitrate, and, when relevant, to continue or stop prestroke antihypertensive drugs temporarily, each for 7 days. Treatment assignment was stratified on the basis of country, stroke type (ischaemic vs haemorrhagic), and immediate prestroke use of antihypertensive treatment; and minimisation on key prognostic baseline variables: age ( $\leq 70$ years $v s>70$ years), sex (female vs male), history of hypertension (no vs yes), history of previous stroke (no vs yes), diabetes (no vs yes), use of nitrate therapy immediately before stroke (no vs yes), stroke severity (Scandinavian stroke scale [SSS] $>30$ vs $\leq 30$ ), total anterior circulation syndrome (no vs yes $){ }^{28}$ systolic blood pressure $(\leq 160 \mathrm{~mm} \mathrm{Hg}$ vs $>160 \mathrm{~mm} \mathrm{Hg}$ ), treatment with recombinant tissue plasminogen activator (yes vs no), feeding status (other vs intravenous fluids or nothing), and time to treatment $(\geq 24 \mathrm{~h}$ vs $<24 \mathrm{~h})$; minimisation included a random element in $5 \%$ of patients. We used stratification and minimisation to ensure that the groups were balanced for prognostic factors, and the random element reduced predictability. The randomisation algorithm then presented a treatment allocation as either glyceryl trinitrate or no glyceryl trinitrate, and, when relevant, continue or stop prestroke antihypertensive drugs. Drugs were prescribed via the site's hospital system. In patients with dysphagia, drugs were given via a nasogastric tube once this had been inserted.

\section{Procedures}

Treatment was started immediately after randomisation, was given daily for 7 days, and consisted of a glyceryl trinitrate dermal patch $(5 \mathrm{mg})$ or no patch. Glyceryl trinitrate patches were sourced locally from any licensed manufacturer, and included the following brands: Deponit-5 (UCB Pharma, Brussels, Belgium; 38\% of sites), Transiderm-Nitro (Novartis, Basel, Switzerland; 28\%), NitroDur (MSD/Schering-Plough, Kenilworth, NJ, USA; 25\%), and Minitran (Meda/3M Healthcare, St Paul, MN, USA; 10\%). Chinese sites obtained patches from a local manufacturer (Wuhan Jianmin Pharmaceutical Group, Wuhan, China). Patients were masked to glyceryl trinitrate by placing a gauze dressing over the patch or over a similar area of skin if they were assigned to no glyceryl trinitrate. The gauze dressing, with or without glyceryl trinitrate patch, was changed every day $(0700-0900 \mathrm{~h})$ with rotation of the site of placement on the shoulders or back. The dose of glyceryl trinitrate was not adjusted during treatment, and patches were left on for $24 \mathrm{~h}$, such that there was no overnight glyceryl-trinitrate-free period. In patients randomly assigned to continue antihypertensive drugs, the same drugs and doses were started at the next normal time when due, and were given for 7 days. When appropriate, drugs were given via a nasogastric tube.

Study drugs were stopped when the patient withdrew consent, for safety reasons, or when unacceptable adverse events developed. Non-trial nitrates and other
For more on the randomisation system see https://www. nottingham.ac.uk/ nszwww/ enos/enostrialdb/enos_login.php antihypertensive drugs were not given during the 7-day treatment period unless the local investigator deemed them necessary. Treatments under investigation were

\begin{tabular}{|c|c|c|c|c|}
\hline & \multicolumn{2}{|l|}{ ENOS } & \multicolumn{2}{|c|}{$\begin{array}{l}\text { Continue vs stop } \\
\text { antihypertensive drugs }\end{array}$} \\
\hline & $\begin{array}{l}\text { Glyceryl } \\
\text { trinitrate }\end{array}$ & $\begin{array}{l}\text { No glyceryl } \\
\text { trinitrate }\end{array}$ & Continue & Stop \\
\hline \multicolumn{5}{|l|}{ Patient characteristics } \\
\hline Number of patients & 2000 & 2011 & 1053 & 1044 \\
\hline Age $\left(\right.$ years) ${ }^{*}$ & $70(12)$ & $70(12)$ & $73(11)$ & $73(11)$ \\
\hline Men* & $1147(57 \%)$ & $1150(57 \%)$ & $528(50 \%)$ & $540(52 \%)$ \\
\hline Pre-morbid $m R S>0$ & $490(25 \%)$ & $536(27 \%)$ & $365(35 \%)$ & $319(31 \%)$ \\
\hline \multicolumn{5}{|c|}{ Time to random treatment assignment } \\
\hline Medan time $(h)^{*}$ & $26(16-36)$ & $26(16-37)$ & $26(16-35)$ & $26(15-37)$ \\
\hline Earlier than $6 \mathrm{~h}$ & $144(7 \%)$ & $129(6 \%)$ & $68(6 \%)$ & $75(7 \%)$ \\
\hline \multicolumn{5}{|l|}{ Geographical region $\neq$} \\
\hline Asia & $276(14 \%)$ & $283(14 \%)$ & $102(10 \%)$ & $100(10 \%)$ \\
\hline UK & $1272(64 \%)$ & $1273(63 \%)$ & $678(64 \%)$ & $674(65 \%)$ \\
\hline Rest of Europe & $322(16 \%)$ & $325(16 \%)$ & $204(19 \%)$ & $203(19 \%)$ \\
\hline Other & $130(7 \%)$ & $130(7 \%)$ & $69(7 \%)$ & $67(6 \%)$ \\
\hline \multicolumn{5}{|l|}{ Medical history } \\
\hline Hypertension & $1287(64 \%)$ & $1320(66 \%)$ & $1001(95 \%)$ & $993(95 \%)$ \\
\hline Taking antihypertensive drugs $\dagger$ & $1057(53 \%)$ & $1081(54 \%)$ & 1047 (99\%) & 1039 (99\%) \\
\hline Stroke & $315(16 \%)$ & $279(14 \%)$ & $212(20 \%)$ & $204(20 \%)$ \\
\hline Transient ischaemic attack & $275(14 \%)$ & $269(13 \%)$ & $181(17 \%)$ & $171(16 \%)$ \\
\hline Ischaemic heart disease & $340(17 \%)$ & $329(16 \%)$ & $255(24 \%)$ & $268(26 \%)$ \\
\hline Peripheral arterial disease & $51(3 \%)$ & $66(3 \%)$ & $37(4 \%)$ & $40(4 \%)$ \\
\hline Diabetes & $343(17 \%)$ & $356(18 \%)$ & $240(23 \%)$ & $244(23 \%)$ \\
\hline HyperlipidaemiaS & $552(28 \%)$ & $546(27 \%)$ & $395(38 \%)$ & $413(40 \%)$ \\
\hline Current smoker ( $n=3846,96 \%)$ & $459(24 \%)$ & $486(25 \%)$ & $185(19 \%)$ & $178(18 \%)$ \\
\hline Alcohol >21 units per week & $140(7 \%)$ & $154(8 \%)$ & $57(5 \%)$ & $47(5 \%)$ \\
\hline $\begin{array}{l}\text { Atrial fibrillation, current or } \\
\text { previous }\end{array}$ & $395(20 \%)$ & $367(18 \%)$ & $308(29 \%)$ & $258(25 \%)$ \\
\hline Nitrate use before stroke & $87(4 \%)$ & $67(3 \%)$ & $70(7 \%)$ & $66(6 \%)$ \\
\hline \multicolumn{5}{|l|}{ Haemodynamics } \\
\hline Systolic blood pressure $(\mathrm{mm} \mathrm{Hg})^{*}$ & 167 (19) & $167(19)$ & 166 (19) & 168 (19) \\
\hline Diastolic blood pressure $(\mathrm{mm} \mathrm{Hg})$ & $90(13)$ & $89(13)$ & $88(13)$ & $89(13)$ \\
\hline $\begin{array}{l}\text { Mean heart rate }(b p m ; n=4007 \text {, } \\
99.9 \%)\end{array}$ & $78(15)$ & $77(15)$ & $77(15)$ & $77(15)$ \\
\hline
\end{tabular}

(Table 1 continues on next page) 


\begin{tabular}{|c|c|c|c|c|}
\hline & \multicolumn{2}{|l|}{ ENOS } & \multicolumn{2}{|c|}{$\begin{array}{l}\text { Continue vs stop } \\
\text { antihypertensive drugs }\end{array}$} \\
\hline & $\begin{array}{l}\text { Glyceryl } \\
\text { trinitrate }\end{array}$ & $\begin{array}{l}\text { No glyceryl } \\
\text { trinitrate }\end{array}$ & Continue & Stop \\
\hline \multicolumn{5}{|l|}{ (Continued from previous page) } \\
\hline \multicolumn{5}{|l|}{ Qualifying event* ${ }^{*} \ddagger$} \\
\hline Ischaemic stroke & $1664(83 \%)$ & $1678(83 \%)$ & $928(88 \%)$ & $904(87 \%)$ \\
\hline Intracerebral haemorrhage & $310(16 \%)$ & $319(16 \%)$ & $119(11 \%)$ & $127(12 \%)$ \\
\hline Stroke, type unknown & 0 & $1(<1 \%)$ & 0 & $1(<1 \%)$ \\
\hline Non-stroke & $26(1 \%)$ & $13(1 \%)$ & $6(1 \%)$ & $12(1 \%)$ \\
\hline $\begin{array}{l}\text { Side of lesion, right }(n=4003 \text {, } \\
99.8 \%)\end{array}$ & $1023(51 \%)$ & $1063(53 \%)$ & $554(53 \%)$ & $520(50 \%)$ \\
\hline SSS score (out of 58$)^{*} \boldsymbol{T}$ & $34(13)$ & $34(13)$ & $32(14)$ & $33(13)$ \\
\hline NIHSS (out of 42), estimated & $11(6)$ & $11(6)$ & $12(6)$ & $11(6)$ \\
\hline GCS $<15$ & $607(30 \%)$ & $622(31 \%)$ & $364(35 \%)$ & $363(35 \%)$ \\
\hline \multicolumn{5}{|l|}{ OCSP classification } \\
\hline Total anterior* & $615(31 \%)$ & $594(30 \%)$ & $361(34 \%)$ & $336(32 \%)$ \\
\hline Partial anterior & $616(31 \%)$ & $635(32 \%)$ & $349(33 \%)$ & $353(34 \%)$ \\
\hline Lacunar & $695(35 \%)$ & $702(35 \%)$ & $301(29 \%)$ & $323(31 \%)$ \\
\hline Posterior & $74(4 \%)$ & $80(4 \%)$ & $42(4 \%)$ & $32(3 \%)$ \\
\hline \multicolumn{5}{|c|}{ Ischaemic causative mechanisms ${ }^{* *}$} \\
\hline Cardioembolic & $365(22 \%)$ & $352(21 \%)$ & $277(30 \%)$ & $230(25 \%)$ \\
\hline Large vessel & $359(22 \%)$ & $383(23 \%)$ & $197(21 \%)$ & $220(24 \%)$ \\
\hline Small vessel & $639(38 \%)$ & $637(38 \%)$ & $305(33 \%)$ & $321(36 \%)$ \\
\hline Other & $342(21 \%)$ & $320(19 \%)$ & $170(18 \%)$ & $160(18 \%)$ \\
\hline Not determined & $34(2 \%)$ & $44(2 \%)$ & $23(2 \%)$ & $14(1 \%)$ \\
\hline \multicolumn{5}{|l|}{ Other treatment } \\
\hline Thrombolytic treatment* & $204(10 \%)$ & $221(11 \%)$ & $123(12 \%)$ & $125(12 \%)$ \\
\hline \multicolumn{5}{|c|}{ 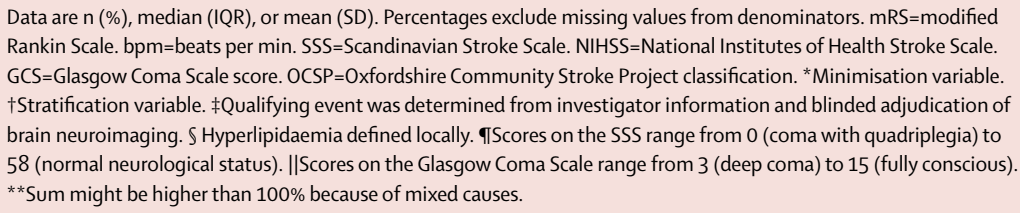 } \\
\hline
\end{tabular}

given in addition to standard care; thrombolysis was permitted in patients with ischaemic stroke according to local practice guidelines at the recruiting site. Systematic use of antihypertensive drugs (all patients, after 7 days), and oral antithrombotic and lipid-lowering drugs (in patients with ischaemic stroke) were recommended for secondary prevention.

The ENOS website was used to record demographic and clinical characteristics. Investigators assessed the severity of the stroke with the SSS (range from 0 to 58 , with lowest scores showing the most severe neurological deficit $^{29}$ at baseline and at 7 days after stroke (or at the time of discharge, if earlier). Blood pressure was measured three times using a validated automated monitor (OMRON Healthcare Company, Kyoto, Japan) supplied to each site; at least one of the three systolic measurements had to be in the range $140-220 \mathrm{~mm} \mathrm{Hg}$ before enrolment. The final diagnosis was confirmed at discharge. Sites were asked to provide a trained member of their research staff who was unaware of treatment assignment to do the post-randomisation assessments in the hospitals. Independent expert assessors who were masked to treatment assignment centrally assessed CT and MRI scans. Independent expert adjudicators who were masked to treatment assignment validated and categorised investigator-reported serious adverse events, including cause-specific deaths. We followed-up in full patients who did not receive their assigned treatment or who did not adhere to the protocol. The coordinating centre of each country (masked to treatment allocation) did the final follow-up centrally at 90 days by telephone. When the patient could not be contacted, a questionnaire covering the same outcome measures was sent by post.

\section{Outcomes}

The primary outcome measure was functional outcome, which we assessed with the mRS at 90 days after enrolment. ${ }^{30}$ Scores on the mRS range from 0 to 6 , with a score of zero indicating no symptoms, five indicating severe dependency, and six denoting death. $\mathrm{mRS}$ is largely determined by motor performance, hence the need for the presence of motor symptoms and signs at enrolment. Prespecified secondary outcomes at day 90 included activities of daily living (Barthel index); ${ }^{31}$ cognition (modified telephone mini-mental state examination ${ }^{32}$ and telephone interview for cognition scale ${ }^{33}$ ); health-related quality of life (European quality of life- 5 dimensions, EQ-5D,,$^{34}$ from which health utility status was calculated [EQ-5D-HUS]); and mood (short Zung depression score $\left.^{35}\right) \cdot{ }^{36}$ At discharge from initial admittance to hospital, investigators recorded duration of stay, and discharge destination (to institution or home).

The safety outcomes ${ }^{26}$ were all-cause case fatality and cause-specific case fatality; early neurological deterioration (defined as a decrease from baseline to day 7 of at least 5 points on the SSS or decrease in consciousness of more than two points on the SSS consciousness domain or both) ${ }^{37}$ recurrent stroke by day 7; episodes of hypotension needing clinical intervention (such as giving intravenous fluids) by day 7; episodes of hypertension needing clinical intervention (such as administration of a treatment to lower blood pressure) by day 7; and serious adverse events.

\section{Statistical analyses}

The original protocol specified analysis of the mRS as a binary variable, with poor outcome defined as an $\mathrm{mRS}$ of higher than 2 at the end of follow-up. ${ }^{26}$ On this basis, we determined the study sample size for the overall trial (glyceryl trinitrate $v s$ no glyceryl trinitrate), and planned to enrol 5000 patients based on a dichotomous analysis. However, during the course of the trial, ordinal approaches to the analysis of the mRS were shown by several research groups to be more efficient statistically. ${ }^{38,39}$ Therefore, the statistical analysis plan, ${ }^{27}$ which was submitted for publication before the start of data analysis and without knowledge of the data, specified that the primary analysis 


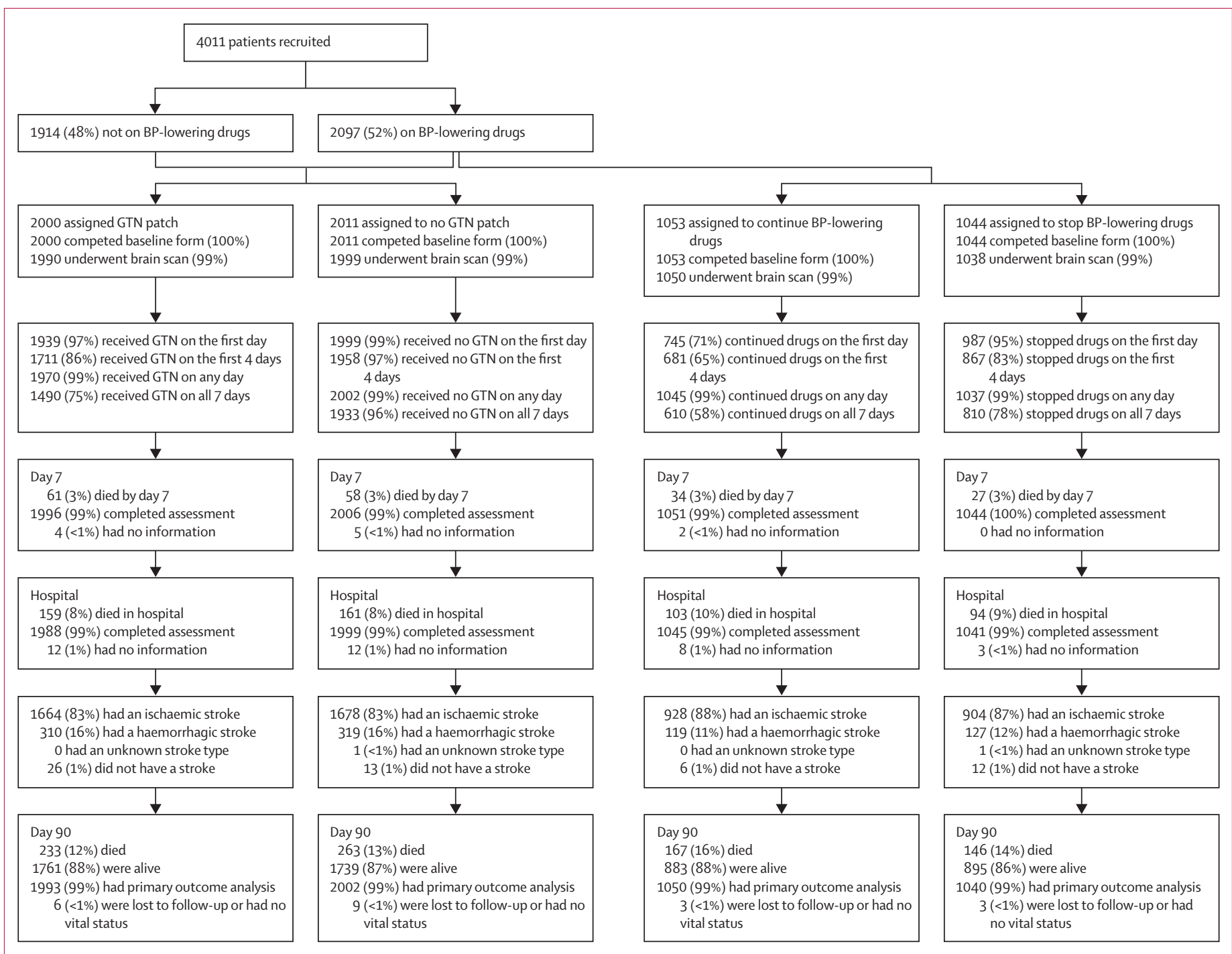

Figure 1: Study profile

Data are $\mathrm{n}(\%)$. ENOS=efficacy of nitric oxide in stroke. $\mathrm{BP}=$ blood pressure. GTN=glyceryl trinitrate.

of the mRS should be done across all seven levels of the $\mathrm{mRS}$ with use of an ordinal statistical approach. As a result, the overall sample size was reduced by the trial steering committee to 3500 patients to detect a shift in the mRS with odds ratio (OR) 0.83 assuming an overall type 1 error rate of $5 \%$ with two-sided significance test, power $90 \%$, adjustment for baseline covariates, and a drop-out rate of $3 \%{ }^{27}$ From the beginning, we assumed that about $50 \%$ of patients would be taking blood pressure-lowering drugs before their stroke and thus go into the comparison of continuation versus stopping of these drugs. A total sample size of 1750 patients would allow a shift in $\mathrm{mRS}$ with an OR of $0 \cdot 80$ (or 1.25 ) to be detected with $80 \%$ power.

We assessed the effect of the treatments on the primary outcome as a shift in mRS score, ${ }^{39}$ and adjusted for the factors used in minimisation at the time of randomisation..$^{40}$ Effects are reported as a common OR with 95\% CI. We calculated OR and significance with ordinal logistic regression after checking that the assumption of proportional odds were not violated. For sensitivity purposes, the primary analyses were also analysed as unadjusted values and as a binary outcome (death or dependency, $\mathrm{mRS}>2$, the original primary outcome). We assessed the heterogeneity of the treatment effects on the primary outcome in prespecified subgroups by adding an interaction term to an unadjusted ordinal logistic regression model. We analysed mortality using Kaplan-Meier and Cox regression models. Because outcomes such as mRS, EQ-5D-HUS, and Barthel index include death as part of their scale (scores of 6 on $\mathrm{mRS}$, 0 on EQ-5D-HUS, and -5 on the Barthel index), and in case treatment was associated with asymmetric effects on death and other outcome measures (eg, more death and less impairment), an extreme value for death was 


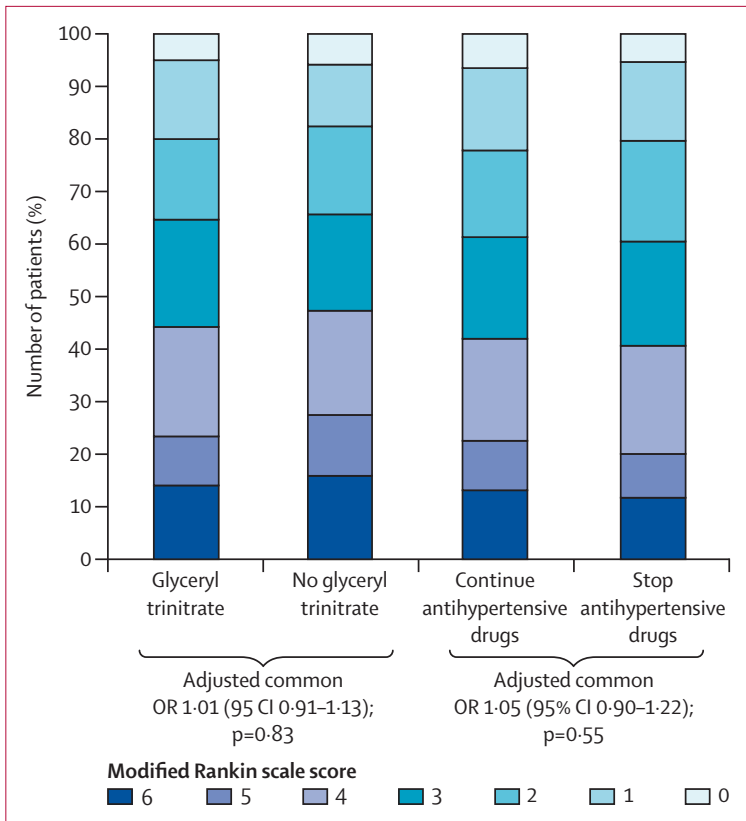

Figure 2: Distribution of modified Rankin Scale scores at 90 days $\mathrm{OR}=$ odds ratio.

added to the other outcome scales: -1 for EQ-VAS, -1 for the modified telephone mini-mental state examination, -1 for SSS, -1 for the telephone interview for cognition scale, and 102.5 on the Zung self-rating depression scale. ${ }^{41}$ The nominal level of significance for all analyses was $\mathrm{p}<0.05$ with no interim analysis. No adjustments were made for multiplicity of testing. We did analyses with SAS version 9.3 according to the intention-to-treat principle. This study is registered, ISRCTN99414122.

\section{Role of the funding source}

The trial was funded by grants from the UK Medical Research Council (G0501797), Efficacy and Mechanism Evaluation (12/62/87), and BUPA foundation, and was sponsored by the University of Nottingham. There was no commercial support for the trial, and antihypertensive drugs were sourced locally at each site. The grant applicants conceived and designed the trial and wrote the the glyceryl trinitrate group and 2011 patients were assigned to the no glyceryl trinitrate group (table 1). 2097 (52\%) patients were taking antihypertensive drugs before their stroke and were included in the continue $(n=1053)$ or stop $(n=1044)$ antihypertensive drugs groups of the trial. The trial was allowed to run to end of funding within its ethics approval, rather than stopping at the 3500 patients required by the sample size calculation. ${ }^{27}$ Most patients were recruited from the UK (table 1). 3995 (>99\%) patients had both vital status and the primary outcome recorded at day 90 (figure 1) and one patient had vital status but no functional outcome.

The treatment groups were well balanced at baseline (table 1). Mean SSS score was 33.7 (13.2; equivalent to a National Institutes of Health Stroke Scale score of $11 \cdot 2[5 \cdot 7]) .{ }^{42}$ Patients who were randomised into the continue versus stop analysis had a more severe phenotype than had those who were not taking antihypertensive drugs before their stroke-they were older, more likely to be women, had higher rates of vascular risk factors, and were less likely to have a normal premorbid Rankin Scale score (table 1). Appendix p 14 lists types and numbers of antihypertensive drugs taken before stroke and baseline feeding status.

Adherence with glyceryl trinitrate patches or control was good. 3938 (98\%) patients received their first treatment as assigned, and $3669(92 \%)$ patients had at least the first 4 days of assigned treatment-a period regarded (a priori) as full treatment (appendix $\mathrm{p} 15$ ). No differences were noted in the use of secondary vascular prophylaxis at day 7 between the two groups (data not shown); overall antiplatelet therapy was used in 3033 (76\%) patients, anticoagulation in 160 (4\%), blood pressure-lowering drugs in 1493 (37\%), and lipid-lowering drugs in 2432 (61\%).

After randomisation, 745 (71\%) of the patients assigned to continue their pre-stroke blood pressure-lowering drugs received their first treatment (figure 1). 306 patients did not receive their first drug dose, of whom 182 (60\%) did not have oral or enteral access, and two did not have data recorded at day 7. By contrast, 987 (95\%) patients assigned to stop their treatment correctly took no tablets on day 1. Similar differences between the continue and stop groups occurred in the first 4 days and for all 7 days. The types of blood pressure-lowering drugs taken after assignment were largely consistent with those taken at baseline in patients randomised to continue drugs (appendix p 16). At day 7, patients in the two groups were taking similar amounts of drugs for secondary vascular prevention-79\% of patients were taking antiplatelet drugs, $5 \%$ taking anticoagulation drugs, and $62 \%$ taking lipid-lowering drugs (data not shown).

Overall mean blood pressure at baseline was 167 (SD 19)/90 (13) $\mathrm{mm} \mathrm{Hg}$ at baseline and reduced in both glyceryl trinitrate and no glyceryl trinitrate groups in the 7 days of treatment (appendix p 20). After the first dose, systolic and diastolic blood pressure were lower in the glyceryl trinitrate 
group by $7 \cdot 0$ (95\% CI 5.6-8.5) $\mathrm{mm} \mathrm{Hg} / 3 \cdot 5$ (2.6-4.4) $\mathrm{mm} \mathrm{Hg}$ (two-sided $\mathrm{p}<0.0001 / \mathrm{p}<0.0001$ ) than in those given no glyceryl trinitrate. The difference in blood pressure between the glyceryl trinitrate and no glyceryl trinitrate groups then diminished and did not differ statistically after day 3 . Heart rate was 1.7 beats per min higher in the glyceryl trinitrate group than in the no glyceryl trinitrate group 1-2 $\mathrm{h}$ after the first treatment $(\mathrm{p}=0.045)$, but not at any later timepoint (data not shown).

For the continue versus stop comparison, blood pressure fell from baseline $(167 / 88 \mathrm{~mm} \mathrm{Hg})$ over 1 week of randomised intervention in both treatment groups, but fell faster in those who continued their blood pressure-lowering drugs (appendix p 22). Mean systolic and diastolic blood pressure levels differed between the treatment groups from day 2 after randomisation; by the end of the treatment phase, patients who continued their drugs had a blood pressure that was lower by $9.5(95 \%$ CI $7 \cdot 2-11 \cdot 8) \mathrm{mm} \mathrm{Hg} / 5 \cdot 0$ (3.7-6.4) $\mathrm{mm} \mathrm{Hg}$ $(\mathrm{p}<0 \cdot 0001 / \mathrm{p}<0 \cdot 0001)$. When considering blood pressure changes by the number of drugs taken before stroke onset, blood pressure started highest and fell most over 7 days in individuals who continued treatment on more drugs (appendix p 17). In patients on a $\beta$ blocker before their stroke, the difference in heart rate between continue and stop increased over the 7 days to 8.5 beats per min higher in the stop group than the continue group. When assessing blood pressure and heart rate across the six treatment groups (taking account of the partial-factorial design), systolic and diastolic blood pressure and heart rate changed most in individuals given glyceryl trinitrate at day 1 and those who continued prestroke antihypertensive drugs at day 7 (appendix p 18).

When adjusted for stratification and minimisation variables, the distribution of mRS between the glyceryl trinitrate group (1993 patients assessed; >99\%) and the no glyceryl trinitrate group (2002 patients assessed; >99\%) did not differ (common OR for a worse outcome with glyceryl trinitrate $1 \cdot 01,95 \%$ CI $0 \cdot 91-1 \cdot 13, \quad \mathrm{p}=0 \cdot 83$; figure 2). A formal goodness-of-fit test gave no evidence that the proportional odds assumption was violated $(p=0 \cdot 11)$. Functional outcome $(m R S)$ did not differ across the six treatment groups when we took account of the partial-factorial design (appendix p 18). When we assessed the primary outcome across prespecified subgroups, significant interactions were present with a shift in the distribution of $\mathrm{mRS}$ in patients randomised glyceryl trinitrate within $6 \mathrm{~h}$ of stroke onset $\left(\mathrm{p}_{\text {interaction }}=0.031\right)$, and in women given glyceryl trinitrate $\left(\mathrm{p}_{\text {interaction }}=0 \cdot 044\right)$ compared with no treatment (figure 3). Although the interaction term was not significant for carotid stenosis, there was no evidence of harm in patients with an occluded carotid artery, although the group size was small. There was no interaction between treatment and age, systolic blood pressure at baseline, type of stroke (ischaemic, haemorrhagic), or continuing versus stopping prestroke antihypertensive drugs (figure 3).

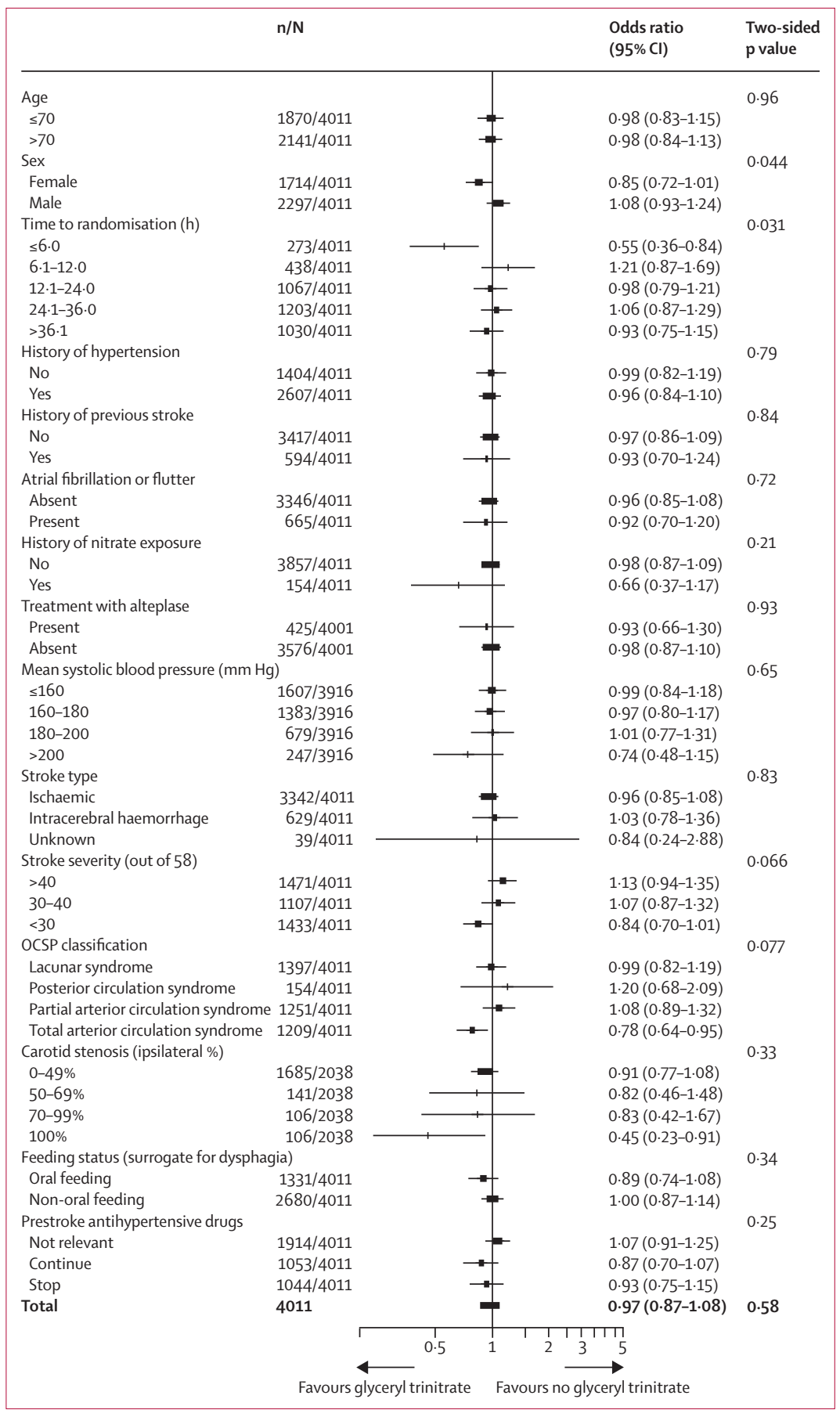

Figure 3: Subgroup analysis of effects on functional outcome at 90 days for glyceryl trinitrate versus no glyceryl trinitrate

Two-sided $\mathrm{p}$ values are for the interaction between subgroup and allocated treatment. OCSP $=0 x f$ ordshire Community Stroke Project. GTN=glyceryl trinitrate.

The cumulative risk of all-cause death (mRS 6) during follow-up did not differ between the group given glyceryl trinitrate and the group not given glyceryl trinitrate (table 2, appendix p 24). Glyceryl trinitrate had no significant effects on any of the secondary outcomes 


\begin{tabular}{|c|c|c|c|c|c|c|c|c|c|c|}
\hline & \multicolumn{5}{|c|}{ Glyceryl trinitrate us no glyceryl trinitrate analysis } & \multicolumn{5}{|c|}{ Continue vs stop analysis } \\
\hline & $\mathrm{N}$ & $\begin{array}{l}\text { Glyceryl } \\
\text { trinitrate } \\
(\mathrm{n}=2000)\end{array}$ & $\begin{array}{l}\text { No glyceryl } \\
\text { trinitrate } \\
(\mathrm{n}=2011)\end{array}$ & OR or $\mathrm{MD}(95 \% \mathrm{Cl})$ & $\begin{array}{l}\text { Two-sided } \\
\text { p value }\end{array}$ & $\mathrm{N}$ & $\begin{array}{l}\text { Continue } \\
(\mathrm{n}=1053)\end{array}$ & Stop $(n=1044)$ & OR or $\mathrm{MD}(95 \% \mathrm{Cl})$ & $\begin{array}{l}\text { Two-sided } \\
\text { p value }\end{array}$ \\
\hline \multicolumn{11}{|l|}{ Day 7 (or discharge) } \\
\hline Death, all cause & 4001 & $61(3 \%)$ & $58(3 \%)$ & $1.12(0.76-1.64)$ & 0.57 & 2095 & $34(3 \%)$ & $27(3 \%)$ & $1.18(0.69-2.00)$ & 0.55 \\
\hline SSS score (out of 58) & 3991 & $39 \cdot 1(16)$ & $38 \cdot 5(16)$ & $0.62(-0.38 \text { to } 1.61)^{*}$ & 0.46 & 2088 & $37 \cdot 1(17)$ & $38.4(16)$ & $-1.25(-2.65 \text { to } 0.16)^{*}$ & 0.28 \\
\hline Neurological deterioration $\dagger$ & 3991 & $177(9 \%)$ & $194(10 \%)$ & $0.88(0.71-1.10)$ & 0.28 & 2088 & $107(10 \%)$ & $105(10 \%)$ & $1.00(0 \cdot 74-1 \cdot 34)$ & 0.99 \\
\hline Recurrent stroke $\ddagger$ & 3997 & $42(2 \%)$ & $31(2 \%)$ & $1 \cdot 37(0.85-2 \cdot 20)$ & 0.19 & 2093 & $30(3 \%)$ & $18(2 \%)$ & $1.64(0.90-3.00)$ & 0.10 \\
\hline $\begin{array}{l}\text { Symptomatic intracranial } \\
\text { haemorrhage } \neq\end{array}$ & 4000 & $22(1 \%)$ & $18(1 \%)$ & $1.20(0.63-2.29)$ & 0.59 & 2095 & $12(1 \%)$ & $11(1 \%)$ & $1.03(0.43-2.44)$ & 0.95 \\
\hline Headache $\ddagger$ & 4000 & $360(18 \%)$ & $170(9 \%)$ & $2 \cdot 39(1.96-2 \cdot 92)$ & $<0.0001$ & 2095 & $123(12 \%)$ & $117(11 \%)$ & $1.11(0.84-1 \cdot 47)$ & 0.46 \\
\hline Hypotension $\neq$ & 4000 & $53(3 \%)$ & $15(1 \%)$ & $3 \cdot 55(1.99-6 \cdot 35)$ & $<0.0001$ & 2095 & $24(2 \%)$ & $16(2 \%)$ & $1.58(0.82-3.02)$ & 0.17 \\
\hline Hypertension $\neq$ & 4000 & $138(7 \%)$ & $155(8 \%)$ & $0.87(0.68-1.11)$ & 0.26 & 2095 & $60(6 \%)$ & $94(9 \%)$ & $0.65(0.46-0.92)$ & 0.015 \\
\hline Serious adverse event & 4011 & $271(14 \%)$ & $261(13 \%)$ & $1.05(0.88-1.26)$ & 0.59 & 2097 & $147(14 \%)$ & $155(15 \%)$ & $0.93(0.73-1.19)$ & 0.56 \\
\hline \multicolumn{11}{|l|}{ Discharge data } \\
\hline Median hospital stay (days) & 3985 & $11(7-25)$ & $11(7-25)$ & $-0.34(-1.81 \text { to } 1.12)^{*}$ & 1.00 & 2086 & $12(7-28)$ & $11(7-26)$ & $1.20(-0.88 \text { to } 3.28)^{*}$ & 0.32 \\
\hline Death or institution & 3986 & $716(36 \%)$ & $761(38 \%)$ & $1.08(0.94-1.25)$ & 0.29 & 2086 & $450(43 \%)$ & $389(37 \%)$ & $0.76(0.62-0.93)$ & 0.008 \\
\hline \multicolumn{11}{|l|}{ Day 90} \\
\hline Death & 3996 & $233(12 \%)$ & $263(13 \%)$ & $0.89(0.72-1.10)$ & 0.27 & 2091 & $167(16 \%)$ & $146(14 \%)$ & $1.09(0.83-1.42)$ & 0.54 \\
\hline Death or institution & 3980 & $554(28 \%)$ & $604(30 \%)$ & $0.88(0.75-1.03)$ & 0.11 & 2083 & $365(35 \%)$ & $323(31 \%)$ & $0.85(0.69-1.06)$ & 0.15 \\
\hline Barthel index (out of 100) & 3970 & $66(38)$ & $63(39)$ & $2.18(-0.23 \text { to } 4.59)^{*}$ & 0.11 & 2076 & $58(41)$ & $62(39)$ & $-3.83(-7.29 \text { to } 0.38)^{*}$ & 0.098 \\
\hline Barthel index $<60$ & 3970 & $654(33 \%)$ & $699(35 \%)$ & $0.90(0.76-1.06)$ & 0.19 & 2076 & $425(41 \%)$ & $365(35 \%)$ & $1.28(1.02-1.59)$ & 0.031 \\
\hline t-MMSE score & 2506 & $11(7)$ & $11(7)$ & $0.33(-0.22 \text { to } 0.88)^{*}$ & 0.13 & 1272 & $9(7)$ & $10(7)$ & $-0.91(-1.70 \text { to } 0.12)^{*}$ & 0.013 \\
\hline TICS-M score & 2322 & $22.43(14.93)$ & $22 \cdot 1(15 \cdot 49)$ & $0.33(-0.91 \text { to } 1.57)^{*}$ & 0.85 & 1179 & $19 \cdot 01(15 \cdot 23)$ & $21.11(15.08)$ & $-2.11(-3.84 \text { to } 0.37)^{*}$ & 0.044 \\
\hline Verbal fluency score & 2366 & $9.31(7.73)$ & $9 \cdot 21(7.93)$ & $0.1(-0.53 \text { to } 0.73)^{*}$ & 0.82 & 1201 & $7.82(7.48)$ & $8.66(7.54)$ & $-0.84(-1.7 \text { to } 0.01)^{*}$ & 0.15 \\
\hline Health utility status & 3952 & $0.49(0.32)$ & $0.48(0.33)$ & $0.01(-0.01 \text { to } 0.03)^{*}$ & 0.87 & 2063 & $0.44(0.33)$ & $0.47(0.33)$ & $-0.03(-0.06 \text { to } 0.00)^{*}$ & 0.24 \\
\hline EQ-VAS & 3440 & $56.5(30.8)$ & $55 \cdot 7(31 \cdot 6)$ & $0.79(-1.29 \text { to } 2.88)^{*}$ & 0.70 & 1759 & $51.8(32 \cdot 4)$ & $54 \cdot 2(31 \cdot 6)$ & $-2.42(-5.41 \text { to } 0.57)^{*}$ & 0.15 \\
\hline ZDS & 3253 & $58.3(23.7)$ & $58.8(24 \cdot 6)$ & $-0.50(-2.15 \text { to } 1.16)^{*}$ & 0.82 & 1659 & $62.0(24.9)$ & $61 \cdot 1(24 \cdot 6)$ & $0.94(-1.44 \text { to } 3.32)^{*}$ & 0.43 \\
\hline Serious adverse event & 4011 & $510(26 \%)$ & $499(25 \%)$ & $1.04(0.90-1.20)$ & 0.62 & 2097 & $308(29 \%)$ & $286(27 \%)$ & $1.10(0.91-1 \cdot 33)$ & 0.35 \\
\hline
\end{tabular}

measured at day 90, including activities of daily living (Barthel index), cognition (modified telephone mini-mental state examination, telephone interview for cognition scale, verbal fluency), quality of life (EQ-5D-HUS, EuroQoL-visual analogue scale), or mood (Zung depression scale; table 2). Patients given glyceryl trinitrate were more likely to have headache or clinical hypotension during treatment than were those not given glyceryl trinitrate. The overall rate of serious adverse events occurring by day 7 (end of treatment) or day 90 did not differ between the two groups (appendix p 19).

There was no difference in the distribution (shift) in the $\mathrm{mRS}$ at day 90 between patients who continued their blood pressure-lowering drugs (1050 patients; $99.7 \%)$ or stopped taking their drugs (1040 patients; >99\%; common OR for a worse outcome in continue group $1 \cdot 05,95 \%$ CI $0 \cdot 90-1 \cdot 22$, $\mathrm{p}=0.55$; figure 2). A formal goodness of fit test gave no evidence that the proportional odds assumption was violated $(\mathrm{p}=0 \cdot 84)$. The effects of the treatments were consistent across all prespecified subgroups (data not shown).
The rates of death from any cause were similar for continue and stop groups (table 2, appendix $\mathrm{p}$ 24). However, patients who continued their blood pressure-lowering drugs were significantly more likely to have died in hospital or been discharged to an institution, and be dead or disabled (Barthel index $<60$ ) by day 90 than were those who stopped treatment (table 2). The continue group had significantly lower cognition scores, whether assessed using the modified telephone mini-mental state examination or telephone interview for cognition scale, than had the stop group. The rate of severe hypertension, as determined by the local investigator, was significantly lower in the continue group than in the stop group (table 2). Although the total number of serious adverse events did not differ between the groups, pneumonia was more common in patients who continued taking their drugs (appendix p 19). Most cases of pneumonia occurred in patients who had dysphagia (97 of 151 patients; 64\%) and many occurred when blood pressure tablets were taken despite the 
patient not having oral or enteral access (46 of 97 patients; $47 \%$ ). The rate of myocardial infarction did not differ for patients who continued versus stopped, either overall or for patients taking a $\beta$ blocker before their stroke (seven $v$ s nine, $\mathrm{p}=0.63$ ). There were no significant differences between the groups in any of the other prespecified secondary outcomes.

\section{Discussion}

ENOS assessed two aspects of blood pressure management in patients with acute stroke and hypertension. There was no effect on functional outcome with either glyceryl trinitrate (compared with no glyceryl trinitrate) or of continuing prestroke antihypertensive drugs compared with stopping them temporarily when started within $48 \mathrm{~h}$ of stroke onset. The neutral results for glyceryl trinitrate were present across many functional outcome measures at day 90 including dependency, activities of daily living, cognition, mood, and quality of life, and might have several explanations. First, if lowering of blood pressure is important for outcome, the difference in blood pressure between the group given glyceryl trinitrate and the group not given glyceryl trinitrate $(7 \cdot 0 / 3 \cdot 5 \mathrm{~mm} \mathrm{Hg})$ might have been insufficient. This difference is twice that reported in the SCAST trial ${ }^{5}(3 \cdot 3 / 1 \cdot 3 \mathrm{~mm} \mathrm{Hg}$ at day 2$)$ in which oral candesartan was associated with a near-negative effect on functional outcome, and about half of that observed in INTERACT-2 ${ }^{8}$ (systolic difference $15 \mathrm{~mm} \mathrm{Hg}$ ) in which intensive lowering in patients with haemorrhagic stroke was associated with a near-positive effect on outcome (panel). Second, lowering of blood pressure might be efficacious only in patients with haemorrhagic stroke, as suggested by INTERACT- $2 .{ }^{8}$ However, candesartan was associated with a worse outcome in the subgroup of patients with haemorrhage in SCAST. ${ }^{44}$ Nevertheless, trials in patients with ischaemic stroke (eg, CATIS $)$, or in which most patients had ischaemic stroke (BEST, ${ }^{23}$ INWEST, ${ }^{24}$ IMAGES, ${ }^{6}$ SCAST $^{5}$ ), were all neutral or negative. Third, treatment might have been started too late with an average time to randomisation of $26 \mathrm{~h}$. Finally, tolerance to glyceryl trinitrate could have developed over the first few days, manifesting as a reduction in the effect of the drug on blood pressure and seen in pilot trials, ${ }^{13,14}$ and so the length of effective treatment might have been insufficient.

Functional outcome was improved in the patients given glyceryl trinitrate within $6 \mathrm{~h}$ and in women compared with men. The observation that treatment might be effective if started very early is compatible with a previous small pilot trial in which glyceryl trinitrate improved functional outcome when given by paramedics outside of the hospital, with an average time to treatment of $55 \mathrm{~min}^{16}$ As in ENOS, glyceryl trinitrate did not change outcome in three hospital-based pilot trials ${ }^{14,15,45}$ when glyceryl trinitrate was given in the acute and subacute phases of stroke. The better effect seen in women might show sex differences in the nitric oxide pathway, as shown experimentally. ${ }^{46}$ The absence of harm in patients with carotid occlusion, although contrasting with theoretical concerns that blood pressure lowering might be harmful in haemodynamically significant arterial disease, is consistent with a pilot trial showing improvement in peri-infarct cerebral blood flow with glyceryl trinitrate. ${ }^{15}$ Whether these interactions show chance or a real effect is not clear. But the planned multicentre phase 3 Rapid Implementation of Glyceryl Trinitrate-2 (RIGHT-2) trial will build on these results and test the safety and efficacy of glyceryl trinitrate when given by paramedics within $4 \mathrm{~h}$ of the stroke ictus.

Although the primary outcome was neutral for the comparison of continue versus stop antihypertensive drugs, patients assigned to continue their blood pressure-lowering drugs did worse than did those who stopped their drugs for several secondary measures of outcome-discharge destination, activities of daily living (measured by Barthel index), and cognition (modified telephone Mini-Mental State Examination and Telephone Interview for Cognition Scale). These observations occurred despite some crossover between groups-ie, some patients assigned to continue treatment did not take their first treatment, usually due to the presence of dysphagia, whereas other patients who were randomly assigned to stop treatment continued it. These secondary findings could simply be due to chance or the effect of comorbidities, and therefore might be of no clinical relevance. However, $80 \%$ of patients continued on drugs that inhibit the renin-angiotensin-aldosterone system-ie, an angiotensin-converting enzyme inhibitor, angiotensin-receptor antagonist, or $\beta$ blocker, or a combination of these drugs. Other trials of reninangiotensin-aldosterone inhibitors during the acute phase of stroke have shown that these drugs were associated with a worse outcome, including BEST ${ }^{22}$ (atenolol, propranolol) and $\mathrm{SCAST}^{23}$ (candesartan). Furthermore, a negative inotropic drug such as a $\beta$ blocker might reduce cerebral perfusion further. However, in a post-hoc analysis of ENOS, we showed no interaction between the primary outcome and whether a reninangiotensin-aldosterone inhibitor was taken or not before the stroke (data not shown).

Most justifications for continuing or stopping treatment, as listed in the introduction, are not supported by the results. Blood pressure did not fall rapidly or by a large amount (as occurred in the INWEST trial $^{24}$ ) in the group assigned to continue treatment, except in a few patients who were being prescribed more than three drugs before their stroke. There was no evidence that the presence of carotid artery stenosis worsened outcome when blood pressure drugs were continued. And any post-randomisation hypertension in the group who stopped their drugs caused no apparent clinical problems. However, pneumonia was more common in patients who continued blood pressure-lowering treatment; although this finding
For more on the RIGHT-2 trial see http://www.right2-trial.org 
Panel: Research in context

\section{Systematic review}

We did a meta-analysis of all randomised controlled trials based on an earlier version published for the SCAST trial. ${ }^{5}$ We searched for reports in the Cochrane Library, PubMed and Embase (up to Dec 11, 2013), and in relevant reference lists for trials of acute stroke in which blood pressure was lowered and for which information about functional outcome was available. For the full list of our search terms see Geeganage and Bath. ${ }^{43}$ Recent large trials were included: INTERACT-2, CATIS, and FAST-Mag..$^{7.8}$ Data were available for 19787 patients in 16 trials. Heterogeneity was tested across four strata: only ischaemic stroke, mixed ischaemic and haemorrhagic stroke, only haemorrhagic stroke, and ENOS Overall there was no effect of lowering blood pressure on functional outcome, odds ratios 1.00 (95\% Cl 0.93-1.97; $\mathrm{p}=0.99$ ). There was no statistical evidence of heterogeneity $\left(\chi^{2} 18 \cdot 6, p=0 \cdot 23 ; l^{2}=19 \%\right.$; appendix $\left.\mathrm{p} 28\right)$.

\section{Interpretation}

There is no evidence that lowering blood pressure improved functional outcome in patients with acute stroke. Although the meta-analysis does not show evidence of heterogeneity, evidence from hyperacute trials of haemorrhagic stroke and from a pilot trial of ultra-acute glyceryl trinitrate suggest that very early lowering of blood pressure might be effective; future trials should focus on treatment within a few hours of stroke onset.

could be due to chance, it might also imply aspiration of those tablets that were continued in the presence of dysphagia. Pneumonia can worsen long-term outcome and therefore might explain poor results in activities of daily living, and death or discharge to an institution.

ENOS has several strengths, including the large sample size, generalisability due to wide inclusion criteria and recruitment of patients from several race and ethnic origin groups across five continents, central concealment of treatment assignment, collection prospectively of several functional outcomes and safety measures such as hypotension and hypertension; central assessment of outcomes at day 90 blinded to treatment assignment, very high rates of follow-up ( $>99 \%$ of patients had their primary outcome recorded), and quality care at stroke units. In addition, the trial was a pragmatic test of real-world approaches to blood pressure management that included individuals over a wide time window representative of routine clinical practice, including patients with ischaemic stroke or haemorrhage, severe or mild stroke, and cortical or lacunar stroke. Glyceryl trinitrate was sourced locally from several manufacturers, further increasing the external validity of the overall trial. The $48 \mathrm{~h}$ time window for inclusion is a strength for the comparison of continue and stop groups since it covers the time during which most patients present with stroke.
However, several limitations are also present. First, glyceryl trinitrate was given in a single-blind design because no manufacturer was able to supply placebo patches. Patient-blinding was obtained with placement of a gauze dressing over a suitable area of skin out of view of the patient (eg, back or shoulders) with or without a glyceryl trinitrate patch underneath, an approach we have used before. ${ }^{15,16,47}$ Although headache occurred in both groups of patients, the rate was double for individuals randomised to glyceryl trinitrate and might have unmasked some patients. Similarly, the continue and stop groups of ENOS had to have an unmasked open-label design because it was not possible to prepare appropriate placebos when investigators did not know what antihypertensive drugs patients would be taking when enrolled. Nevertheless, outcomes measured at day 90 were assessed centrally by trained staff who were masked to treatment assignment and who were not involved in hospital care of enrolled patients. Second, some patients assigned to glyceryl trinitrate did not receive it for the recommended minimum treatment period of 4 days-reasons included earlier discharge from hospital or death, an adverse event such as headache, or withdrawal of consent. Adherence with treatment allocation was also not optimum for continue versus stop, particularly among patients allocated to stop antihypertensives. However, the resulting crossover would have been to dilute the difference in outcomes between the groups, not to increase it or change the direction of the effect. Third, the first dose of transdermal glyceryl trinitrate lowered blood pressure by only $7 \cdot 0 / 3 \cdot 5 \mathrm{~mm} \mathrm{Hg}$, a smaller effect than was seen in our pilot trials, in which reductions at $1-2 \mathrm{~h}$ after treatment were $18-23 \mathrm{~mm} \mathrm{Hg} .{ }^{15,16}$ The explanation for this discrepancy is not clear, but it is likely that the timing of blood pressure measurements relative to administration of glyceryl trinitrate was far more variable in this large pragmatic international trial than in the earlier explanatory single-centre studies. Supportive of this assertion, treatment with glyceryl trinitrate was associated with clinical hypotension in some patients. Fourth, some patients will have been taking blood pressure-lowering drugs for reasons other than the management of hypertension-although individual reasons were not collected in ENOS, $\alpha$-receptor antagonists are used in men with benign prostatic hypertrophy, $\beta$ blockers are used for heart rate management in patients with atrial fibrillation, and angiotensin-modifying drugs and diuretics are used for the control of heart failure. $103(5 \%)$ patients randomly assigned to continue versus stop did not have a history of high blood pressure before their stroke. And finally, the trial started in 2001 at a time when modern medical interventions (stroke units, thrombolytics, statins) were not commonly available. However, 3182 (79\%) patients were recruited from 2008 so most will have benefitted from modern guideline-based care. 
Most patients with acute stroke have high blood pressure, an independent risk factor for a poor outcome. Although this and other trials of vasodepressant interventions were neutral, ${ }^{6,7}$ their results suggest that lowering blood pressure is, at least, free of serious hazard. Antihypertensive drugs will reduce blood pressure more quickly than will the spontaneous reduction that occurs over the first few days after stroke and will allow secondary prevention. Transdermal administration of a drug in acute stroke is advantageous since oral treatment is confounded by the presence of severe dysphagia in up to $50 \%$ of patients, whereas intravenous therapy needs intensive monitoring; additionally, transdermal treatment can be stopped and re-started according to clinical need.

In conclusion, we noted no benefit for lowering of blood pressure with glyceryl trinitrate in patients with acute stroke and raised blood pressure. The results are compatible with a neutral meta-analysis of previous trials of several strategies to lower blood pressure in patients with acute ischaemic, haemorrhagic, or mixed stroke. ${ }^{5}$ Although lowering of blood pressure might not be beneficial when started at an average of $26 \mathrm{~h}$ after stroke onset, glyceryl trinitrate has acceptable safety, including in patients with carotid stenosis, and potential benefits when started within $6 \mathrm{~h}$ of stroke onset. There was no difference in functional outcome measured using the mRS when we compared groups who continued versus stopped prestroke antihypertensive drugs. However, some secondary outcomes were worse in the group who continued treatment, although whether this finding is due to chance or is a real effect is not clear. Overall, ENOS provides no evidence for the strategy of immediately continuing prestroke blood pressure-lowering drugs after admission to hospital; indeed, such a policy might have a deleterious effect. The main implication for practice is that it seems reasonable to withhold blood pressure-lowering drugs until patients with an acute stroke are medically and neurologically stable, and have suitable oral or enteral access to allow safe drug reintroduction. Nevertheless, post-acute blood pressure control is important to reduce the risk of subsequent vascular events and drugs will need to be restarted.

\section{Contributors}

All authors contributed to the interpretation of the results and writing of this report. PMWB wrote and prepared the first draft of the manuscript, with input from the writing committee, all of whom approved the decision to submit the manuscript for publication.

\section{Writing committee}

Philip M W Bath, Lisa Woodhouse, Polly Scutt, Kailash Krishnan, Joanna M Wardlaw, Daniel Bereczki, Nikola Sprigg, Eivind Berge, Maia Beridze, Valeria Caso, Christopher Chen, Hanne Christensen, Ronan Collins, Anwar El Etribi, Ann Charlotte Laska, Kennedy R Lees, Serefnur Ozturk, Steve Phillips, Stuart Pocock, H Asita de Silva, Szabolcs Szatmari, Sally Utton.

Declaration of interests

We declare no competing interests.

\section{Acknowledgments}

This trial was primarily funded by the UK Medical Research Council. Other funders who supported the trial were the Agency for Science, Technology, and Research (Singapore), BUPA Foundation (UK), Hypertension Trust (UK), Queen Elizabeth II Health Sciences Centre Research Fund (Canada), Reichstadt family (UK), and The Stroke Association (UK, through its funding of the Division of Stroke, University of Nottingham, Nottingham, UK). We thank the coinvestigators and research staff at the participating sites for their support. ENOS acknowledges the support of the UK National Institute for Health Research, through the Stroke Research Network; the large recruitment in the UK would not have been possible without network support. PMWB is Stroke Association Professor of Stroke Medicine. JMW was supported by a collaboration between the Scottish Funding Council (SFC) and the Scottish Imagine Network: a Platform for Scientific Excellence.

\section{References}

1 Leonardi-Bee J, Bath PMW, Phillips SJ, Sandercock PAG, for the IST Collaborative Group. Blood pressure and clinical outcomes in the International Stroke Trial. Stroke 2002; 33: 1315-20.

2 Willmot M, Leonardi-Bee J, Bath PM. High blood pressure in acute stroke and subsequent outcome: a systematic review. Hypertension 2004; 43: 18-24.

3 Sprigg N, Gray LJ, Bath PM, et al. Relationship between outcome and baseline blood pressure and other haemodynamic measures in acute ischaemic stroke: data from the TAIST trial. J Hypertens 2006; 24: 1413-17.

4 Geeganage C, Tracy M, England T, et al. Relationship between baseline blood pressure parameters (including mean pressure, pulse pressure, and variability) and early outcome after stroke: data From the Tinzaparin in Acute Ischaemic Stroke Trial (TAIST). Stroke 2011; 42: 491-93.

5 Sandset EC, Bath PM, Boysen G, et al. The angiotensin-receptor blocker candesartan for treatment of acute stroke (SCAST): a randomised, placebo-controlled, double-blind trial. Lancet 2011; 377: 741-50.

6 Intravenous Magnesium Efficacy in Stroke (IMAGES) Study Investigators. Magnesium for acute stroke (Intravenous Magnesium Efficacy in Stroke trial): randomised controlled trial. Lancet 2004; 363: 439-45.

7 He J, Zhang Y, Xu T, et al. Effects of immediate blood pressure reduction on death and major disability in patients with acute ischemic stroke: The CATIS Randomized Clinical Trial. JAMA 2014; 311: 479-89.

8 Anderson CS, Heeley E, Huang Y, et al. Rapid blood-pressure lowering in patients with acute intracerebral hemorrhage. N Engl J Med 2013; 368: $2355-65$

9 Geeganage C, Bath PMW. Relationship between therapeutic changes in blood pressure and outcomes in acute stroke: a metaregression. Hypertension 2009; 54: 775-81.

10 Willmot MR, Bath PMW. The potential of nitric oxide therapeutics in stroke. Expert Opin Investig Drugs 2003; 12: 455-70.

11 Willmot M, Murphy S, Leonardi-Bee J, Bath P. Systematic review of nitric oxide donors and L-arginine in experimental stroke: effects on infarct size and cerebral blood flow. Nitric Oxide 2005; 12: 141-49.

12 Butterworth RJ, Cluckie A, Jackson SH, Buxton-Thomas M, Bath PM. Pathophysiological assessment of nitric oxide (given as sodium nitroprusside) in acute ischaemic stroke. Cerebrovasc Dis 1998; 8: 158-65.

13 Bath PMW, Pathansali R, Iddenden R, Bath FJ. The effect of transdermal glyceryl trinitrate, a nitric oxide donor, on blood pressure and platelet function in acute stroke. Cerebrovasc Dis 2001; 11: 265-72.

14 Rashid P, Weaver C, Leonardi-Bee J, Bath F, Fletcher S, Bath P. The effects of transdermal glyceryl trinitrate, a nitric oxide donor, on blood pressure, cerebral and cardiac hemodynamics, and plasma nitric oxide levels in acute stroke. J Stroke Cerebrovasc Dis 2003; 12: 143-51.

15 Willmot M, Ghadami A, Whysall B, Clarke W, Wardlaw J, Bath PM. Transdermal glyceryl trinitrate lowers blood pressure and maintains cerebral blood flow in recent stroke. Hypertension 2006; 47: 1209-15.

16 Ankolekar S, Fuller M, Cross I, et al. Feasibility of an ambulance-based stroke trial, and safety of glyceryl trinitrate in ultra-acute stroke: the rapid intervention with glyceryl trinitrate in Hypertensive Stroke Trial (RIGHT, ISRCTN66434824). Stroke 2013; 44: 3120-28. 
17 Neal B, MacMahon S, Chapman N, for the Blood Pressure Lowering Treatment Trialists' Collaboration. Effects of ACE inhibitors, calcium antagonists, and other blood-pressure-lowering drugs: results of prospectively designed overviews of randomised trials. Lancet 2000; 356: 1955-64.

18 Rashid P, Leonardi-Bee J, Bath P. Blood pressure reduction and the secondary prevention of stroke and other vascular events: a systematic review. Stroke 2003; 34: 2741-49.

19 Lees KR, Dyker AG. Blood pressure control after acute stroke. J Hypertens 1996; 14 (suppl 6): S35-38.

20 Bath PMW, Weaver C, Iddenden R, Bath FJ. A trial of blood pressure reduction in acute stroke. Age Ageing 2000; 29: 554-55.

21 Robinson TG, Potter JF, Ford GA, et al, for the COSSACS Investigators. Effects of antihypertensive treatment after acute stroke in the Continue or Stop Post-Stroke Antihypertensives Collaborative Study (COSSACS): a prospective, randomised, open, blinded-endpoint trial. Lancet Neurol 2010; 9: 767-75.

22 Sandset EC, Bath PM, Boysen G, et al, for the SCAST Study Group. The angiotensin-receptor blocker candesartan for treatment of acute stroke (SCAST): a randomised, placebo-controlled double-blind trial. Lancet 2011; 377: 741-50.

23 Barer DH, Cruickshank JM, Ebrahim SB, Mitchell JR. Low dose beta blockade in acute stroke ("BEST" trial): an evaluation. BMJ 1988 296: 737-41.

24 Wahlgren NG, MacMahon DG, de Keyser J, Indredavik B, Ryman T, for the INWEST Study Group. Intravenous Nimodipine West European Stroke Trial (INWEST) of nimodipine in the treatment of acute ischaemic stroke. Cerebrovasc Dis 1994; 4: 204-10.

25 Fischberg GM, Lozano E, Rajamani K, Ameriso S, Fisher MJ. Stroke precipitated by moderate blood pressure reduction. J Emerg Med 2000; 19: 339-46.

26 The ENOS Trial Investigators. Glyceryl trinitrate vs control, and continuing vs. stopping temporarily prior antihypertensive therapy, in acute stroke: rationale and design of the Efficacy of Nitric Oxide in Stroke (ENOS) trial (ISRCTN99414122). Int J Stroke 2006; 1: 245-49.

27 Bath PM, Houlton A, Woodhouse L, Sprigg N, Wardlaw J, Pocock S for the ENOS Trialists. Statistical analysis plan for the 'Efficacy of Nitric Oxide in Stroke' (ENOS) trial. Int J Stroke 2014; 9: 372-74.

28 Bamford J, Sandercock P, Dennis M, Burn J, Warlow C. Classification and natural history of clinically identifiable subtypes of cerebral infarction. Lancet 1991; 337: 1521-26.

29 Lindenstrom E, Boysen G, Christiansen LW, Rogvi Hansen B, Nielsen PW. Reliability of scandinavian neurological stroke scale. Cerebrovascular Diseases 1991; 1: 103-07.

30 Lees KR, Bath PMW, Schellinger PD, et al. Contemporary outcome measures in acute stroke research: choice of primary outcome measure. Stroke 2012; 43: 1163-70

31 Sulter G, Steen C, de Keyser J. Use of the Barthel Index and modified Rankin Scale in acute stroke trials. Stroke 1999; 30: 1538-41.

32 Metitieri T, Geroldi C, Pezzini A, Frisoni GB, Bianchetti A, Trabucchi M. The ITLE-MMSE: an Italian telephone version of the mini-mental state examination. Int J Geriatr Psychiatry 2001; 16: $166-67$
33 Desmond DW, Tatemichi TK, Hanzawa L. The telephone interview for cognitive status (TICS): reliability and validity in a stroke sample. Int J Geriatr Psychiatry 1994; 9: 803-07.

34 Whynes DK, Sprigg N, Selby J, Berge E, Bath PM. Testing for differential item functioning within the EQ-5D. Med Decis Making 2013; 33: 252-60.

35 Zung WWK. A self-rating depression scale. Arch Gen Psychiatry 1965; 12: 63-70.

36 Schellinger PD, Bath PMW, Lees K, et al. Assessment of addtional endpoints relevant to the benefit of patients after stroke-what, when, where, in whom. Int J Stroke 2012; 7: 227-30.

37 Bath PMW, Lindenstrom E, Boysen G, et al. Tinzaparin in acute ischaemic stroke (TAIST): a randomised aspirin-controlled trial. Lancet 2001; 358: 702-10.

38 Bath PM, Gray LJ, Collier T, Pocock S, Carpenter J, for the Optimising Analysis of Stroke Trials (OAST) Collaboration. Can we improve the statistical analysis of stroke trials? Statistical re-analysis of functional outcomes in stroke trials. Stroke 2007; 38: 1911-15.

39 Bath PM, Lees KR, Schellinger PD, et al. Statistical analysis of the primary outcome in acute stroke trials. Stroke 2012; 43: 1171-78.

40 Weir CJ, Lees KR. Comparison of stratification and adaptive methods for treatment allocation in an acute stroke clinical trial. Stat Med 2003; 22: 705-26.

41 Ankolekar S, Renton C, Sare G, Ellender S, Sprigg N, Wardlaw JM, Bath PM; ENOS Trial Investigators. Relationship between poststroke cognition, baseline factors, and functional outcome: data from "efficacy of nitric oxide in stroke" trial. J Stroke Cerebrovasc Dis 2014; 23: $1821-29$.

42 Gray LJ, Ali M, Lyden PD, Bath PM. Interconversion of the National Institutes of Health Stroke Scale and Scandinavian Stroke Scale in acute stroke. J Stroke Cerebrovasc Dis 2009; 18: 466-68.

43 Geeganage C, Bath PM. Interventions for deliberately altering blood pressure in acute stroke. Cochrane Database Syst Rev 2008; 4: CD000039.

44 Jusufovic M, Sandset EC, Bath PM, Berge E; for the Scandinavian Candesartan Acute Stroke Trial Study Group. Blood pressure-lowering treatment with candesartan in patients with acute hemorrhagic stroke. Stroke 2014; published online Sept 25. http://dx.doi.org/10.1161/STROKEAHA.114.006433.

45 Bath PM, Pathansali R, Iddenden R, Bath FJ. The effect of transdermal glyceryl trinitrate, a nitric oxide donor, on blood pressure and platelet function in acute stroke. Cerebrovasc Dis 2001; 11: 265-72.

46 Dachtler J, Hardingham NR, Fox K. The role of nitric oxide synthase in cortical plasticity is sex specific. J Neurosci 2012; 32: 14994-99.

47 Rashid P, Weaver C, Leonardi-Bee JA, Fletcher S, Bath FJ, Bath PMW. The effects of transdermal glyceryl trinitrate, a nitric oxide donor on blood pressure, cerebral and cardiac haemodynamics and plasma nitric oxide levels in acute stroke. J Stroke Cerebrovasc Dis 2003; 13: 143-51. 